\title{
Influence of Study Abroad on University Knowledge Innovation
}

\author{
Shao Yanfeng ${ }^{1,2}$ \\ ${ }^{1}$ School of Economics and Management, Beijing University of Aeronautics and \\ Astronautics, Beijing 100191, China \\ ${ }^{2}$ Graduate School, Beijing University of Aeronautics and Astronautics, Beijing \\ 100191, China \\ shaoyf@buaa.edu.cn
}

\begin{abstract}
The current research of university knowledge transfer in the tide of globalization is summarized. A mathematical model of transnational knowledge transfer between universities is constructed based on economic analysis method. Extreme value calculation for differential equations and equilibrium value concept are employed to prove that higher participation rate of domestic institutions in knowledge innovation will lead to greater efforts in personal knowledge innovation.
\end{abstract}

Keywords: study abroad, university, knowledge innovation, knowledge transfer, model

\section{Introduction}

The total number of people who have the experience of studying abroad amounted to 2.2451 million from 1978 to the end of 2011 in China. 72.02\% of them, about 818, 400 people, have returned to China after finishing their study abroad since the 1978 Reform. Most of them graduated from oversea universities. As everyone knows, university is the main source of knowledge innovation, and the young students undertake the historical mission of building an innovation-oriented nation. Therefore, university knowledge transfer plays a significant role on knowledge innovation system.

In the last ten years it can be found that a large number of papers examine knowledge transfer activities between universities and industry (business sector) [1-3], but transnational knowledge transfer brought by studying abroad was neglected.

The elements and characteristics of knowledge transfer in the process of studying abroad are analyzed. A knowledge transfer mathematical model is established to explore the influence of studying abroad on university knowledge transfer based on a mathematical analysis method.

\section{A Review on University Transnational Knowledge Transfer}

\subsection{The Number of Students Studying Abroad Increasingly with Years}

The trend of studying abroad in China began with the government-funded studying abroad programs.. China began a new era of sending students to developed countries on a large scale from 1978. The Ministry of Education of China submitted "A Report on the Amount of Students Studying in Canada" on July 11th, 1978. The first 52 visiting scholars set off for the United States on December 26th. It was a crucial first move toward the world since the reform and opening up.

As time passed by, the government's sponsorship inclined to be in favor of students, rather than visitors and the government-funded personnel studying abroad became increasingly younger. In 2007, Chinese government began to implement "The National Project of Sending Government-sponsored Graduate Students to Build High-level 
Universities" which is the largest scale government-sponsored student studying abroad project since the establishment of P. R. China. According to this plan, Chinese government will systematically select 5000 graduate students from 49 top universities and send them to first-class universities to study every year from 2007 to 2011.

Thanks to the government-sponsored policy, more and more university students got the opportunities to study abroad, which became an important part of the university internationalization strategy.

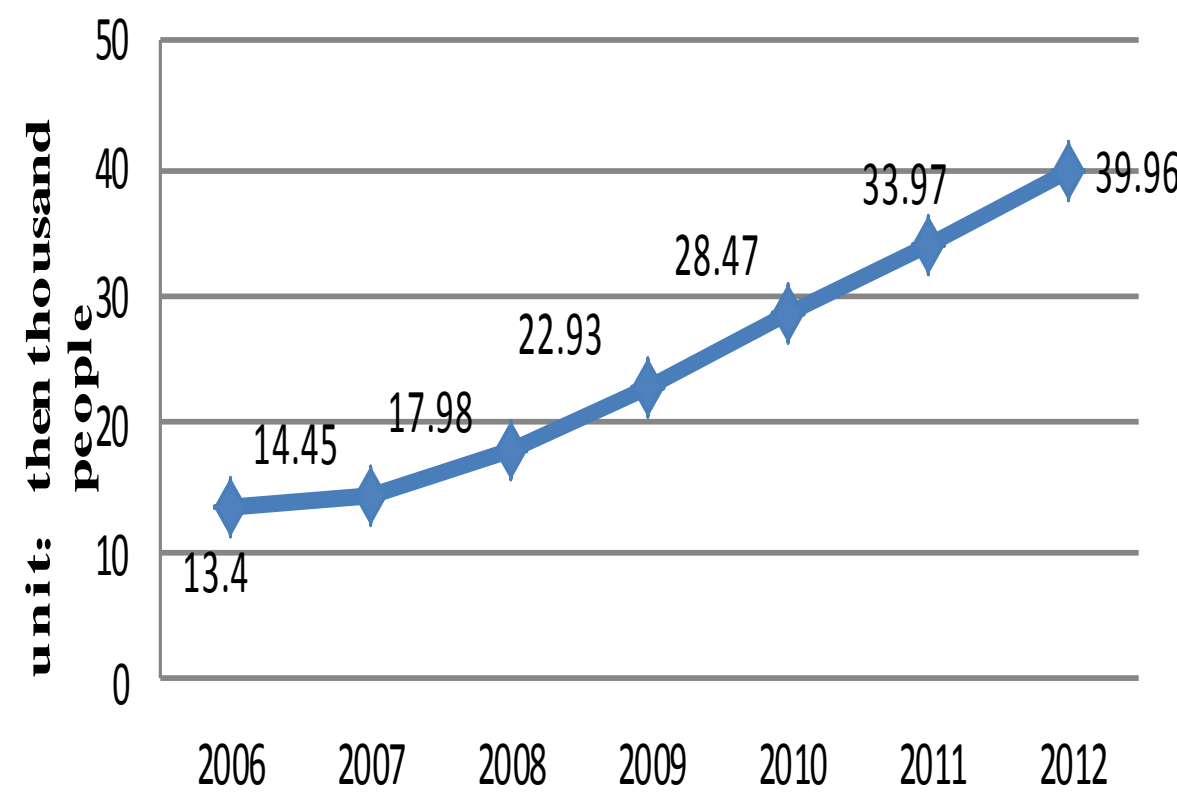

\section{Figure 1. The Number of Chinese Students Studying Abroad from 2006 to 2012}

\subsection{The sSniversity Knowledge Transfer}

In the last ten years it can be found that a large number of papers examine knowledge transfer activities between universities and industry (business sector) [1-3]. A growing body of research suggests that many institutions in universities are developing policies and measures to increase knowledge transfer between universities and industry [4-6]. But less attention was paid to the knowledge transfer between universities and other important stakeholders such as students, alumni, society and public institutions and the essential features and interactive methods in it. Further transnational knowledge transfer brought by studying abroad was neglected.

A landscape of international knowledge exchange is rapidly formed as a new open innovation mode with the increase of economic globalization. This open innovation mode describes the universities' need for using internal and external knowledge and the knowledge transfer channel to remain competitive in the market. The universities are going through a big transition from the ivory towers to entrepreneurs to contributing to the nation's innovation [7]. Universities show a growing demand that they use knowledge to commercialize intellectual property and technology. At the policy level, by supporting public-private partnerships and open innovation strategy, the government is trying to create vibrant small and medium enterprises (SME) to accelerate the commercialization of technology and actively promote cooperation between universities and enterprises. University-industry-government triple helix model of innovation is becoming a powerful 
tool of the state which develops an innovative mechanism to strengthen the contact between private and public research institutions [7-8].

Under the background of open innovation, universities are increasingly being portrayed as the core of knowledge production entity, and can play a greater role by providing knowledge to commercial and industrial enterprises in the process of boosting innovation and development [9-10]. Knowledge is possessed or created not only by the private companies or organizations, but also from external sources (such as universities), and this is considered a key factor in the formation of modern innovation process and innovation system [11-13]. In practice, universities have shown their increasing importance in university knowledge transfer. Many governments and agencies all over the world are turning their attention to the university knowledge creation and knowledge transfer, and which has been regarded as a policy design of developing innovative, sustainable, prosperous regional and national economy [12], [14-17].

Duan et al. (2010) [18] believe that there are four levels in knowledge transfer: the individual level, the intra-organizational level, the inter-organizational level and the multinational level. For universities, there have been four main categories of transfer partners: enterprises, public institutions (universities, international associations, high schools etc.), students and third parties (alumni, society, non-governmental organizations etc.). In view of the above, university internationalization is the highest of the four levels in knowledge transfer (the multinational level), and transfer partners involved are public institutions (foreign universities), students and the third parties. When university students are studying abroad, they contribute to knowledge transfer as individuals as well as to knowledge transfer between nations and third parties.

\section{The Construction of Study Abroad Knowledge Transfer Model}

With the development of globalization, knowledge flows between countries and oversea students are more and more frequently. Oversea students become an important way for transnational knowledge transfer. Studying in foreign countries, they learn local customs and communication patterns, expand their skills and knowledge base, enlarge their social network, and drive collaboration between institutions at home and abroad. The implicit and explicit knowledge are transferred through personal behavior (studying abroad) and bring benefits to institutions at home and abroad.

As the main body of knowledge innovation, the major task of universities and scientific research units is to engage in research and development work ( $R \& D$ work) based on the objectives of economic development and national strategy need. From the view of economics, the R \& D work is a process of inputing and outputing of producing knowledge. Therefore, we can refer to the economics analysis method to analyze the process of studying abroad knowledge transfer.

Study abroad knowledge transfer model is shown in Figure 2.

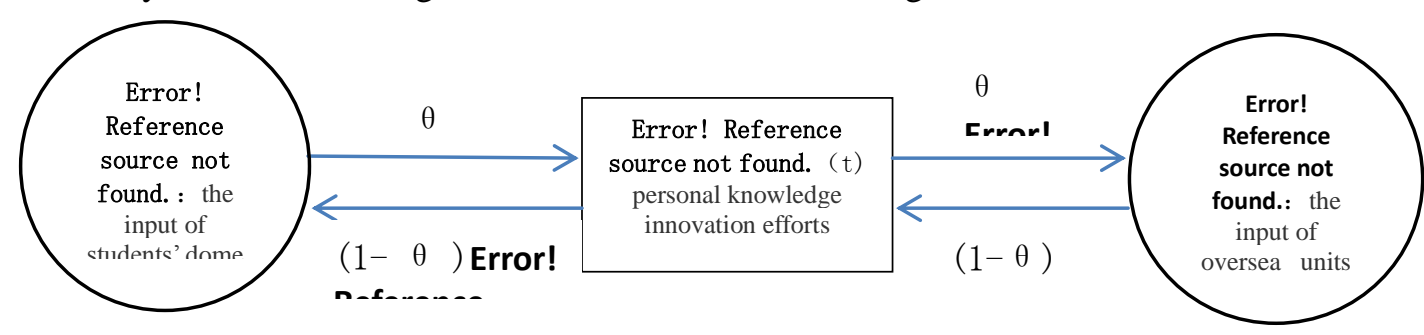

Figure 2. Study Abroad Knowledge Transfer Model

It is assumed that the performance of studying abroad on knowledge innovation is $\mathrm{P}$, the input of students' domestic units on knowledge innovation is $f_{d}$, the input of oversea units on knowledge innovation is $f_{a}$, and personal knowledge innovation efforts is $f_{p}$ 
$(t)$. The initial performance value is assumed as $f_{0}$, and the domestic units participation rate on personal knowledge innovation efforts is expressed as $\theta(0 \leq \theta \leq 1)$. Then the performance function is formulated as:

$$
P=f_{0}+f_{d}^{\alpha} f_{a}^{\beta} f_{p}^{\gamma}+\varepsilon_{1}
$$

Where $\alpha, \beta, \gamma$ are constants larger than 0 , they are called knowledge innovation efforts elasticity, which can measure the change level of the knowledge innovation performance $\mathrm{P}$ with innovation input. The environmental uncertainty is expressed as $\varepsilon_{1}$. Where $\alpha$ is domestic investment elasticity coefficient, $\beta$ is international unit investment elasticity coefficient, and $\gamma$ is personal efforts elasticity coefficient. With larger $\alpha$ comes greater domestic unit investment impact on knowledge innovation performance. With larger $\beta$ comes greater international unit investment impact on knowledge innovation performance. With larger Error! Reference source not found. comes greater personal efforts impact on knowledge innovation performance. Where $\gamma>\alpha+\beta>1$ means that the cooperation efforts is larger than summation of isolated efforts and the domestic unit and international unit knowledge innovation investment is benefit to overseas knowledge innovation performance.

The knowledge innovation performance without overseas efforts $P_{0}$ is formulated as:

$$
P_{0}=f_{0}+\varepsilon_{2}
$$

The overseas knowledge innovation increment $\Delta \mathrm{P}$ then becomes:

$$
\Delta P=P-P_{0}=f_{d}^{\alpha} f_{a}^{\beta} f_{p}^{\gamma}+\left(\varepsilon_{1}-\varepsilon_{2}\right)
$$

The expected value of $\varepsilon_{1}-\varepsilon_{2}$ is assumed as 0 , then the expected performance function $\widehat{\Delta \mathrm{P}}$ becomes:

$$
\widehat{\Delta P}=f_{d}^{\alpha} f_{a}^{\beta} f_{p}^{\gamma}
$$

With the largest knowledge innovation efforts level comes the greatest expected performance function as the results of knowledge innovation.

The domestic and oversea units knowledge innovation investment marginal revenues are expressed as $\mathrm{M}_{\mathrm{d}}$ and $\mathrm{M}_{\mathrm{a}}$ respectively. The innovation marginal revenues increase with the innovation efficiency incensements. The domestic unit participation rate on personal knowledge innovation efforts is assumed as $\theta$, where $0 \leq \theta \leq 1$.

\section{The Formula Derivation and Analysis}

Based on the above assumptions, the expected domestic and international unit innovation revenues $\widehat{\pi_{d}}$ and $\widehat{\pi_{a}}$ can be expressed respectively as: 


$$
\begin{aligned}
& \widehat{\pi_{d}}=M_{d} f_{d}^{\alpha} f_{a}^{\beta} f_{p}^{\gamma}-f_{p} \theta \\
& \widehat{\pi_{a}}=M_{a} f_{d}^{\alpha} f_{a}^{\beta} f_{p}^{\gamma}-f_{p}(1-\theta)
\end{aligned}
$$

The total expected revenue of domestic and international unit innovation $\pi$ can be obtained from Eq. (3) and Eq. (4):

$$
\hat{\pi}=\widehat{\pi_{d}}+\widehat{\pi_{a}}=\left(M_{d}+M_{a}\right) f_{d}^{\alpha} f_{a}^{\beta} f_{p}^{\gamma}-f_{p}
$$

The max personal knowledge innovation effort $f_{p}^{\prime}$ can be obtained from the expected revenue function of domestic unit innovation when the first order partial derivative is 0 .

$$
\frac{\partial \widehat{\pi}_{d}}{\partial f_{p}}=\gamma M_{d} f_{p}^{(\gamma-1)} f_{d}^{\alpha} f_{a}^{\beta}-\theta
$$

The max personal knowledge innovation effort $\mathrm{f}_{\mathrm{p}}^{t}$ can be obtained by the solution of Eq. (6) :

$$
f_{p}^{\prime}=\left(\frac{\theta}{\gamma M_{d} f_{d}^{a} f_{a}^{\beta}}\right)^{\frac{1}{\gamma-1}}
$$

The $\theta$ partial derivative with Eq.(7) is:

$$
\frac{\partial f_{p}^{\prime}}{\partial \theta}=\frac{1}{\gamma-1}\left(\frac{1}{\gamma M_{d} f_{d}^{\alpha} f_{a}^{\beta}}\right)^{\frac{1}{\gamma-1}} \theta^{\left(\frac{1}{\gamma-1}-1\right)}>0
$$

It is shown in Eq. (8) that the optimal level personal knowledge innovation efforts are proportional to domestic unit participation rate.

A domestic unit optimal participation rate $\theta^{*}$ is determined by the domestic unit innovation revenue function, and then we have:

$$
\begin{aligned}
& \max _{\theta} \widehat{\pi_{a}^{*}}=M_{a} f_{d}^{a} f_{a}^{\beta} f_{p}^{* \gamma}-f_{p}^{*}(1-\theta) \\
& \text { St } \quad f_{p}^{*}=\left(\frac{\theta}{\gamma M_{d} f_{d}^{a} f_{a}^{\beta}}\right)^{\frac{1}{\gamma-1}}
\end{aligned}
$$

\section{$0 \leq \theta \leq 1$}

The domestic institutions environment participation equilibrium value $\theta^{*}$ and personal knowledge innovation effort equilibrium value $\mathrm{f}_{\mathrm{p}}^{*}$ can be obtained by the solution of Eq. (9) respectively. 


$$
\begin{aligned}
\theta^{*} & =\left\{\begin{array}{lr}
\frac{M_{a}}{M_{a}+\gamma M_{d}} & M_{a}>0 \\
0 & \text { 其他 }
\end{array}\right. \\
f_{p}^{*} & =\left[\frac{M_{a}}{\gamma\left(M_{a}+\gamma M_{d}\right) M_{d} f_{d}^{\alpha} f_{a}^{\beta}}\right]^{\frac{1}{\gamma-1}}
\end{aligned}
$$

The total revenue equilibrium value $\pi^{*}$ can be obtained by putting $\mathrm{f}_{\mathrm{p}}^{*}$ into the total knowledge innovation revenue function Eq. (5):

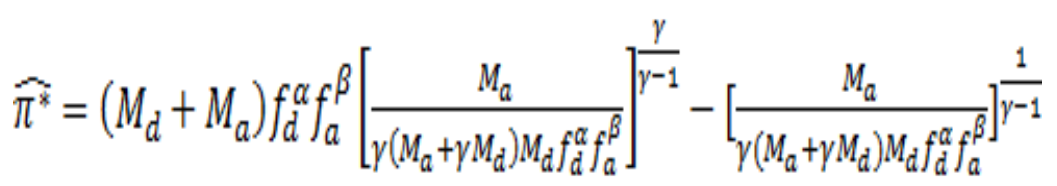

\section{Conclusion}

It is shown in Eq. (5) that domestic and foreign institutions knowledge innovation must make greater efforts to get the same benefits if personal knowledge innovation efforts are poor. It provides a motivation to personal knowledge innovation efforts. Therefore, we can reach the following conclusions:

Conclusion1: A specific motivation system is necessary for encouraging personal knowledge innovation efforts, rather than simply offering conditions and opportunities.

It is shown in Eq. (7) that if domestic institutions are willing to make more efforts in knowledge innovation, the individuals will also make more efforts. So the domestic units' participation rate can be used as a decisive factor of personal efforts in studying abroad knowledge innovation. It also shows that when the domestic units' participation rate is higher, the knowledge innovation performance is higher. However, individuals must make greater contributions to knowledge innovation projects as a result of their increasing efforts on the knowledge innovation. It follows that:

Conclusion 2: In the process of knowledge innovation, if the domestic units' participation rate is higher, the level of personal knowledge innovation efforts is higher.

Through the observation of the max personal knowledge innovation effort $\mathrm{f}_{\mathrm{p}}^{\circ}$ and Eq. (8), we have:

Conclusion 3: The level of the max personal knowledge innovation effort is proportional to domestic institutions' participation rate.

Through the observation of personal knowledge innovation effort equilibrium value $\mathrm{f}_{\mathrm{p}}^{*}$, we have:

Conclusion 4: Personal knowledge innovation effort equilibrium value $\mathrm{f}_{\mathrm{p}}^{*}$ is a function of investment marginal revenue, it is also a function of knowledge innovation efforts of domestic and foreign institutions.

Through the observation of the domestic institutions environment participation equilibrium value $\theta^{*}$ in Eq. (10), we have:

Conclusion 5: $\theta^{*}$ is a function of investment marginal revenue as well as a function of personal efforts elasticity coefficient.

\section{References}

[1] K. Agrawal, "University-to-industry knowledge transfer: literature review and unanswered questions", International Journal of Management Reviews, vol. 3, no. 4, (2001), pp. 285-302.

[2] M. D. Santoro and S. Gopalakrishnan, "The institutionalization of knowledge transfer activities within industry-university collaborative ventures", Journal of Engineering and Technology Management, vol. 17, no. 3-4, (2000), pp. 299-319. 
[3] S. Yusuf, "Intermediating knowledge exchange between universities and businesses", Research Policy, vol. 37, no. 8, (2008), pp. 1167-1174.

[4] L. G. Tornatzky, "Technology-based economic development in Atlanta and Georgia: The role of university partnerships", Industry and Higher Education, vol. 16, no. 1, (2002), pp. 19-26.

[5] M. Perkmann and K. Walsh, International Journal of Management Reviews, vol. 9, no.4, (2007), pp. 259-280.

[6] A. Abreu, "Anatomy of context: A framework analysis for archival knowledge organization", Proceedings of the American Society for Information Science and Technology, vol. 45, no.1, (2008), pp. $1-5$.

[7] H. Etzkowitz, "Introduction: Technology transfer and the East European transition", Science and Public Policy, vol. 27, no. 4, (2000), pp. 230-234.

[8] L. M. Ranga, J. Miedema and R. Jorna, "Enhancing the innovative capacity of small firms through triple helix interactions: challenges and opportunities", Technology Analysis and Strategic Management, vol. 20, no. 6, (2008), pp. 697-716.

[9] R. Thanki, "How Do We Know the Value of Higher Education to Regional Development?", Regional Studies, vol. 33, no. 1, (1999), pp. 84-89.

[10] R. Huggins, A. Johnston and R. Steffenson, "Universities, knowledge networks and regional policy", Contemporary Economic Policy, vol. 1, no. 2, (2008), pp. 321-340.

[11]

[12] F. C. Reeman, “The 'national system of innovation' in historical perspective”, Cambridge Journal of Economics, vol. 19, no. 1, (1995), pp. 5-24.

[13] C. H. Whesbrough, "The era of open innovation", MIT Sloan Management Review, vol. 44, no. 3, (2003), pp. 35-41.

[14] L. S. Helen and B. S. Sharmistha, "University-Industry Interactions: the Case of the UK Biotech Industry", Industry and Innovation, vol. 13, no. 4, (2006), pp. 371-392.

[15] H. Etzkowitz, "The European entrepreneurial university”, Industry and Higher Education, vol. 17, no. 5, (2003), pp. 325-336.

[16] J. Drucker and H. Goldstein, "Assessing the Regional Economic Development Impacts of Universities: A Review of Current Approaches", International Regional Science Review, vol. 30, no. 1, (2007), pp. 20-46.

[17] M. Wellings, "British Methodism: What circuit ministers really think", Theology, vol. 111, no. 859, (2008), pp. 73-74

[18] A. Kitson, BSc(Hons) and D. Phil, FRCN, "Knowledge translation and guidelines: a transfer, translation or transformation process?", International Journal of Evidence-Based Healthcare, vol. 7, no. 2, (2009), pp. 124-139.

[19] Y. Q. Duan, "Identifying key factors affecting transnational knowledge transfer", Information and Management, vol. 47, no. 7-8, (2010), pp. 356-363.

\section{Authors}

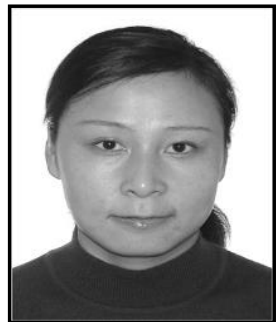

Shao Yanfeng, female, the Han nationality, associate research fellow, a Ph.D candidate. 
International Journal of $u-$ and e- Service, Science and Technology Vol.9, No. 5 (2016) 